\title{
The Detection of Thyroid Nodules in Prediabetes Population and Analysis of Related Factors
}

\author{
Xingyu Chang $\mathbb{D}^{1,2, *}$ \\ Yaqi Wang ${ }^{1,2, *}$ \\ Songbo $\mathrm{Fu}^{\mathrm{I}, 2}$ \\ Xulei Tang ${ }^{1,2}$ \\ Jingfang Liu ${ }^{1,2}$ \\ Nan Zhao ${ }^{1,2}$ \\ Gaojing Jing ${ }^{1,2}$ \\ Qianglong Niu ${ }^{1,2}$ \\ Lihua $\mathrm{Ma}^{\mathrm{I}, 2}$ \\ Weiping Teng ${ }^{3}$ \\ Zhongyan Shan ${ }^{3}$ \\ 'Department of Endocrinology, First \\ Hospital of Lanzhou University, Lanzhou, \\ Gansu, 730000, People's Republic of \\ China; ${ }^{2}$ Gansu Provincial Endocrine \\ Disease Clinical Medicine Research \\ Center, Gansu, 730000, People's Republic \\ of China; ${ }^{3}$ Department of Endocrinology, \\ The First Affiliated Hospital of China \\ Medical University, Shenyang, Liaoning \\ Province, I0I100, People's Republic of \\ China
}

*These authors contributed equally to this work
Purpose: To explore the detection of thyroid nodules (TN) and related influencing factors in the population of prediabetes (PreDM) in northwest China's Gansu Province.

Materials and Methods: A multi-stage stratified cluster random sampling method was used to select adult Han residents in Gansu Province for investigation, and recorded the clinical data of the subjects. The $\chi^{2}$ test was used to analyze the difference in TN detection rate of the PreDM population. Logistic regression analyzed the risk factors of TN in the PreDM population.

Results: This study included 2659 people with normal glucose tolerance (NGT) and PreDM, of which 440 people were detected with TN. Among the PreDM population, the TN detection rate was higher than in the NGT population $(24.48 \%$ vs $15.00 \% ; P<0.05)$. The detection rate of $\mathrm{TN}$ in the impaired fasting glucose (IFG), impaired glucose tolerance (IGT) and IFG+IGT group was also significantly higher than that in the NGT population $\left(X^{2}=4.117, X^{2}=13.187, X^{2}=13.016\right.$, all $\left.P<0.05\right)$, and of which, the IFG+IGT group was the highest $(32.20 \%)$. The general trend of TN in the IFG, IGT and PreDM population all increased with age. General data showed that BMI, waist-to-height ratio, waist circumference, TG, TC, LDL-C, FPG, $2 \mathrm{~h}$ PG, HbAlc and TSH indicators in the TN group were higher than those in the Non-TN group $(P<0.05)$. The logistic regression suggested that the risk factors for TN in the PreDM population were female, age increase, high SP, high TSH, high FPG, high LDL-C, hypertension and family history of diabetes (all $P<0.05$ ).

Conclusion: The detection rate of TN in the PreDM population is high, especially in the IFG+IGT population. Middle-aged and elderly people with hypertension and abnormal glucose and lipid metabolism should be treated reasonably and regularly, and their TN should be screened and followed up.

Keywords: prediabetes, thyroid nodules, risk factors

\section{Introduction}

PreDM is the transition state between normal glucose tolerance and diabetes. ${ }^{1}$ In recent years, with the rapid development of the economy, changes in people's lifestyle and dietary structure, the prevalence of PreDM in adults in China has shown a rapid growth trend in the past decade, from $15.5 \%$ to $35.2 \%$, and its prevention and treatment need to be paid great attention to. ${ }^{2,3} \mathrm{TN}$ is a sporadic disease caused by the abnormal proliferation of local thyroid cells. The detection rate of TN in adults in China is about $20.4 \%$, and there is a large disease base. ${ }^{4,5}$ Epidemiological investigation shows that the detection rate of $\mathrm{TN}$ in people with abnormal glucose metabolism is significantly increased, suggesting that there may be a certain connection between the two diseases. ${ }^{6}$ At present, the study of TN is
Correspondence: Songbo Fu Department of Endocrinology, First Hospital of Lanzhou University, Lanzhou, Gansu, 730000, People's Republic of China

Tel +86-13993/22257

Email fusb@Izu.edu.cn 
mostly concentrated in the diabetic population, while the study of the PreDM population is less. This study focuses on the analysis of $\mathrm{TN}$ detection and related influencing factors in the adult PreDM population in Gansu Province, and provides reference ideas for clinical prevention of TN in the PreDM population.

\section{Materials and Methods Research Object}

Selection method: a multi-stage stratified cluster random sampling method was used in Gansu Province. From September 4, 2016 to February 1, 2017, adult Han residents living in Lanzhou, Longnan, Dingxi, Baiyin and Linxia Prefecture for more than five years were randomly selected. Age 18-87 years, average (41.52 \pm 14.34$)$ years. Exclusion criteria: (1) previous history of thyroid diseases; (2) patients who had received iodine-containing contrast agent examination or taken amiodarone in the past three months; (3) history of exposure to radioactive substances; (4) patients with severe liver and renal insufficiency; (5) patients with severe heart-brain dysfunction; (6) patients with malignant tumors; (7) diabetic patients; (8) pregnant women or lactating women; and (9) have taken drugs that interfere with blood lipids, blood pressure and thyroid function in the past 3 months, such as glucocorticoids, metoclopramide, propranolol and so on. Informed consent was signed by all participants (Medical Ethics Research Committee of the First Affiliated Hospital of China Medical University, AF-SOP-07-1.0-01).

\section{Method}

\section{Common Data}

Gender, age, height, weight, body mass index (BMI), waist circumference, heart rate, systolic blood pressure (SP), diastolic blood pressure (DP), family history of diabetes and history of hypertension were recorded.

\section{Biochemical Index}

(1) Blood lipid-related indexes: total cholesterol (TC, $\mathrm{mmol} / \mathrm{L})$, triglyceride (TG, mmol/L), high density lipoprotein cholesterol (HDL-C, mmol/L), low density lipoprotein cholesterol (LDL-C, mmol/L); (2) blood glucose-related indicators: fasting plasma glucose (FPG, mmol/L), $2 \mathrm{~h}$ blood glucose after OGTT load (2h PG, mmol/L), glycosylated hemoglobin (HbAlc, \%); (3) thyroid function examination: thyroid-stimulating hormone (TSH, mIU/L), anti-thyroid peroxidase antibody (TPOAb, IU/mL), and anti-thyroid globulin antibody (TgAb, IU/mL); and (4) other tests: urinary iodine (UIC, ug/L).

\section{Prediabetes Diagnostic Criteria and Grouping}

According to Guidelines for the Prevention and Treatment of Type 2 Diabetes in China (WHO 1999), ${ }^{1}$ the diagnostic criteria are as follows: (1) normal glucose tolerance (NGT): $\mathrm{FPG}<6.1 \mathrm{mmol} / \mathrm{L}$ and $2 \mathrm{~h} \mathrm{PG}<7.8 \mathrm{mmol} / \mathrm{L}$; (2) prediabetes (PreDM): (a) impaired fasting glucose (IFG): $6.1 \mathrm{mmol} / \mathrm{L} \leq \mathrm{FPG}<7.0 \mathrm{mmol} / \mathrm{L}$ and $2 \mathrm{~h} \mathrm{PG}<7.8 \mathrm{mmol} / \mathrm{L}$, (b) impaired glucose tolerance (IGT): $7.8 \mathrm{mmol} / \mathrm{L} \leq 2$ $\mathrm{hPG}<11.1 \mathrm{mmol} / \mathrm{L}$ and $\mathrm{FPG}<6.1 \mathrm{mmol} / \mathrm{L}$, (c) impaired glucose tolerance combined with impaired fasting glucose (IFG+IGT): $6.1 \mathrm{mmol} / \mathrm{L} \leq \mathrm{FPG}<7.0 \mathrm{mmol} / \mathrm{L}$ and $7.8 \mathrm{mmol} /$ $\mathrm{L} \leq 2 \mathrm{hPG}<11.1 \mathrm{mmol} / \mathrm{L}$; and (3) diabetes: $\mathrm{FPG} \geq 7.0 \mathrm{mmol} /$ $\mathrm{L}$ or $2 \mathrm{~h} P G \geq 11.1 \mathrm{mmol} / \mathrm{L}$.

\section{Thyroid Nodule}

(1) Thyroid ultrasound examination: the examiner was supine, so that the head was reared and the shoulder was as high as possible, resulting in complete exposure of the anterior cervical region. The unified purchased B-ultrasound machine was used, GE General Motors, model LOGIQ $\alpha 100$ (probe resolution $7.5 \mathrm{~Hz}$ ). Ultrasound diagnosis evaluation was performed by two senior doctors with rich clinical experience to observe the size and morphology of TN.

(2) Diagnosis of thyroid nodules: the diagnosis of thyroid nodules was performed according to the Guidelines for diagnosis and treatment of adult thyroid nodules and differentiated thyroid carcinoma released by the American Thyroid Association in 2015. ${ }^{7}$ The subjects were divided into the thyroid nodule group (TN group) and the non-thyroid nodule group (Non-TN group) according to whether they had thyroid nodule or not.

\section{Statistical Method}

SPSS 25.0 software was used for analysis. Normal distribution measurement data were expressed as $(\mathrm{x} \pm \mathrm{s})$. Two independent sample $t$ test was used for comparison between the two groups. Count data were described by frequency. The difference in prevalence between the two groups was compared by the $\chi^{2}$ test. Logistic regression analysis model was used to analyze the possible risk factors of PreDM and its different subtypes, and the test level $\alpha=0.05$. Non-normal distribution data were expressed as median (Median, M), 25th, 75th percentile (P25, P75). Mann-Whitney $U$ test was used between the two groups. 
All the comparison results were statistically significant $(P<0.05)$.

\section{Results}

\section{Baseline Data Distribution of Survey Population}

Baseline data of 2659 subjects, including region, education level, occupation, annual family income, are shown in Table 1.

\section{Comparison of TN Detection Rate Between PreDM and Its Subtypes}

In this study, a total of 2659 subjects were selected from NGT (2226 cases) and PreDM (433 cases), among which 440 patients with TN were found (187 males and 253 females). The results showed that the detection rate of $\mathrm{TN}$ in the PreDM population was 24. 48\% (106/433). The detection rate of TN in male, female and total in the PreDM population were all significantly higher than that in the NGT population $\left(X^{2}=12.87, X^{2}=11.81, X^{2}=23.57\right.$, all $P<0$. 001). Among all subtypes of PreDM, the detection rate of TN in the IFG+IGT population was the highest (32.20\%), followed by IGT (23.34\%) and IFG (22.99\%) as shown in Table 2.

\section{Distribution of TN Detection Rate in Different Age Groups Under Different Glucose Metabolism}

The detection rates of TN in different subtypes of PreDM (IFG, IGT, IFG+IGT) were significantly higher than those in NGT $\left(X^{2}=4.117, X^{2}=13.187, X^{2}=13.016\right.$, all $\left.P<0.05\right)$. There was a statistically significant difference in the detection rate of TN among different age groups (PreDM, IFG, IGT) of different glucose metabolism groups $(P<0.001)$, and they all showed an overall upward trend with age, as shown in Table 3.

\section{Comparison of General Data Between TN Group and Non-TN Group}

The subjects were divided into TN and Non-TN. The results showed that the age, BMI, SP, DP, waist-height ratio, waist circumference, FPG, $2 \mathrm{~h}$ PG, TG, TC, LDL-C, $\mathrm{HbA1c}, \mathrm{TSH}, \mathrm{TPOAb}, \mathrm{TgAb}$ of TN group were higher than those of the Non-TN group $(P<0.05)$, and the urinary iodine level of the TN group was lower than that of the Non-TN group $(P<0.05)$, as shown in Table 4 .
Table I Baseline Data Distribution of Survey Population

\begin{tabular}{|c|c|c|}
\hline Characteristics & $\begin{array}{c}\text { Number of } \\
\text { Cases }\end{array}$ & $\begin{array}{l}\text { Composition } \\
\text { Ratio }\end{array}$ \\
\hline \multicolumn{3}{|l|}{ Area } \\
\hline Urban & 1224 & 46.03 \\
\hline Rural & 1435 & 53.97 \\
\hline \multicolumn{3}{|l|}{ Education } \\
\hline Illiteracy & 358 & 13.46 \\
\hline Primary school & 226 & 8.50 \\
\hline Junior high school & 433 & 16.82 \\
\hline $\begin{array}{l}\text { Senior high school/technical } \\
\text { secondary school }\end{array}$ & 420 & 15.79 \\
\hline Undergraduate/junior college & 1146 & 43.09 \\
\hline Postgraduate & 76 & 2.96 \\
\hline \multicolumn{3}{|l|}{ Profession } \\
\hline Worker & 674 & 25.35 \\
\hline Farmer & 1021 & 38.40 \\
\hline Staff & 628 & 23.62 \\
\hline Housework & 57 & 2.14 \\
\hline Student & 84 & 3.15 \\
\hline Other & 195 & 7.33 \\
\hline \multicolumn{3}{|l|}{ Family income (thousand yuan) } \\
\hline$\leq 5$ & 78 & 2.93 \\
\hline $5 \sim 10$ & 167 & 6.28 \\
\hline $10 \sim 30$ & 584 & 21.96 \\
\hline $30 \sim 50$ & 518 & 19.48 \\
\hline $50 \sim 100$ & 831 & 31.25 \\
\hline$>100$ & 481 & 18.09 \\
\hline
\end{tabular}

\section{Logistic Regression Analysis of Risk Factors for TN in Prediabetes Population with Different Subtypes}

In the population of PreDM and its different subtypes, with TN as the dependent variable, the independent variables were screened by single factor analysis, and the multivariate analysis was performed. Finally, gender, age, BMI, SP, DP, TSH, family history of diabetes, $\mathrm{HbA1c}$, hypertension, LDL-C were independent variables. The multivariate logistic regression equation showed that the risk factors for TN in the PreDM population were gender, age, high SP, high TSH, high FPG, family history of diabetes, hypertension, and high LDL-C (all $P<0.05)$. The risk factors for TN in the IFG population were gender, age, and high TSH (all $P<0.05$ ). The risk factors for $\mathrm{TN}$ in the IFG population were gender and age (all $P<0.05$ ). The risk factors for TN in the IFG+IGT population were age, high SP, high HbAlc, hypertension, and high LDL-C (all $P<0.05$ ), as shown in Table 5 . 
Table 2 Comparison of TN Detection Among Preiabetes and Its Subtypes Population

\begin{tabular}{|c|c|c|c|c|c|c|c|c|}
\hline & \multicolumn{2}{|c|}{ Male } & \multicolumn{2}{|c|}{ Female } & \multirow[t]{2}{*}{$P^{*}$} & \multirow[t]{2}{*}{$\chi^{2}$} & \multicolumn{2}{|c|}{ Total } \\
\hline & $\mathbf{n}$ & TN, n (\%) & $\mathbf{n}$ & TN, n (\%) & & & $\mathbf{n}$ & TN, n (\%) \\
\hline PreDM & 229 & $49(2 \mathrm{I} .40)$ & 204 & $57(27.94)$ & 0.114 & 2.50 & 433 & $106(24.48)$ \\
\hline IFG & 44 & II (25.00) & 43 & $9(20.93)$ & 0.652 & 0.20 & 87 & $20(22.99)$ \\
\hline IGT & 150 & $28(18.67)$ & 137 & 39 (28.47) & 0.050 & 3.84 & 287 & $67(23.34)$ \\
\hline IFG+IGT & 35 & $10(28.57)$ & 24 & $9(37.50)$ & 0.471 & 0.52 & 59 & $19(32.20)$ \\
\hline NGT & 1114 & I 38 (12.39) & 1112 & $196(17.63)$ & 0.001 & 11.97 & 2226 & $334(I 5.00)$ \\
\hline$P^{\#}$ & \multicolumn{2}{|c|}{$<0.001$} & \multicolumn{2}{|c|}{$<0.001$} & \multirow{2}{*}{\multicolumn{2}{|c|}{ - }} & \multicolumn{2}{|c|}{$<0.001$} \\
\hline$x^{2}$ & \multicolumn{2}{|c|}{12.87} & \multicolumn{2}{|c|}{11.81} & & & \multicolumn{2}{|c|}{23.57} \\
\hline Total & 1343 & 187 (13.92) & 1316 & 253 (19.37) & $<0.001$ & 13.53 & 2659 & 440 \\
\hline
\end{tabular}

Notes: $\mathrm{n}$ : male or female; TN, n (\%): patients with thyroid nodules, respective prevalence; $P^{*}$ : comparison of TN between male and female patients; $P^{\#}$ : comparison of TN between PreDM and NGT population.

Table 3 Distribution of TN Detection Rate in Different Age Groups Under Different Glucose Metabolism

\begin{tabular}{|c|c|c|c|c|c|c|c|c|c|c|}
\hline \multirow{3}{*}{$\begin{array}{l}\text { Group } \\
\text { Age }\end{array}$} & \multirow{2}{*}{\multicolumn{2}{|c|}{ NGT }} & \multirow{2}{*}{\multicolumn{2}{|c|}{ PreDM }} & \multicolumn{6}{|c|}{ Prevalence of TN in Different Subtypes of PreDM } \\
\hline & & & & & \multicolumn{2}{|r|}{ IFG } & \multicolumn{2}{|r|}{ IGT } & \multicolumn{2}{|r|}{ IFG+ IGT } \\
\hline & $\mathbf{n}$ & $\begin{array}{l}n-T N \\
(n, \%)\end{array}$ & $\mathbf{n}$ & n-TN (n, \%) & $\mathbf{n}$ & $\begin{array}{c}\text { n-TN (n, } \\
\text { Constituent } \\
\text { Ratio, \%) }\end{array}$ & $\mathbf{n}$ & $\begin{array}{c}\text { n-TN (n, } \\
\text { Constituent } \\
\text { Ratio, \%) }\end{array}$ & $\mathbf{n}$ & $\begin{array}{c}\text { n-TN (n, } \\
\text { Constituent } \\
\text { Ratio, \%) }\end{array}$ \\
\hline $18 \sim 30$ & 727 & $47(6.46)$ & 32 & $4(12.50)$ & 9 & $2(50.00)$ & 22 & $2(50.00)$ & I & $0(0.00)$ \\
\hline $31 \sim 40$ & 563 & $68(12.08)$ & 56 & $5(8.93)$ & 10 & I (20.00) & 40 & $4(80.00)$ & 6 & $0(0.00)$ \\
\hline $41 \sim 50$ & 484 & $64(13.22)$ & 109 & $9(8.26)$ & 27 & $2(22.22)$ & 72 & $6(66.66)$ & 10 & I (II.II) \\
\hline $51 \sim 60$ & 257 & 71 (27.63) & 122 & $33(27.05)$ & 24 & $6(18.18)$ & 83 & $21(63.64)$ & 15 & $6(18.18)$ \\
\hline$\geq 61$ & 195 & $84(43.08)$ & 114 & $55(48.25)$ & 17 & $9(16.36)$ & 70 & $34(6 I .82)$ & 27 & $12(2 \mid .82)$ \\
\hline$x^{2}$ & \multicolumn{2}{|r|}{199.158} & \multicolumn{2}{|r|}{60.591} & \multicolumn{2}{|r|}{13.328} & \multicolumn{2}{|r|}{40.616} & \multicolumn{2}{|r|}{7.854} \\
\hline$P$ & \multicolumn{2}{|r|}{$<0.001$} & \multicolumn{2}{|r|}{$<0.001$} & \multicolumn{2}{|r|}{0.010} & \multicolumn{2}{|r|}{$<0.001$} & \multicolumn{2}{|r|}{0.097} \\
\hline Total & 2226 & $334(15.00)$ & 433 & $106(24.48)$ & 87 & $20\left(22.99^{\#}\right)$ & 287 & $67\left(23.34^{\#}\right)$ & 59 & $19\left(32.20^{\#}\right)$ \\
\hline
\end{tabular}

Notes: $\mathrm{n}$ : total number; n-TN: number of patients with thyroid nodules; \%: prevalence rate; $P$ : comparison of TN detection among different ages; ${ }^{\#}$ comparison of TN between IFG/IGT/IFG+IGT and NGT, $P<0.05$.

\section{Discussion}

With the continuous development of the social economy and the improvement of people's living standards, the prevalence of PreDM in Chinese residents has shown a rapid growth trend, and abnormal glucose metabolism has gradually become an important influencing factor for many diseases. ${ }^{2}$ At the same time, as one of the most common thyroid diseases, the harmfulness of $\mathrm{TN}$ has attracted the attention of the whole society, but the influence mechanism between glucose metabolism and TN is not clear, which needs further study. ${ }^{8}$ 


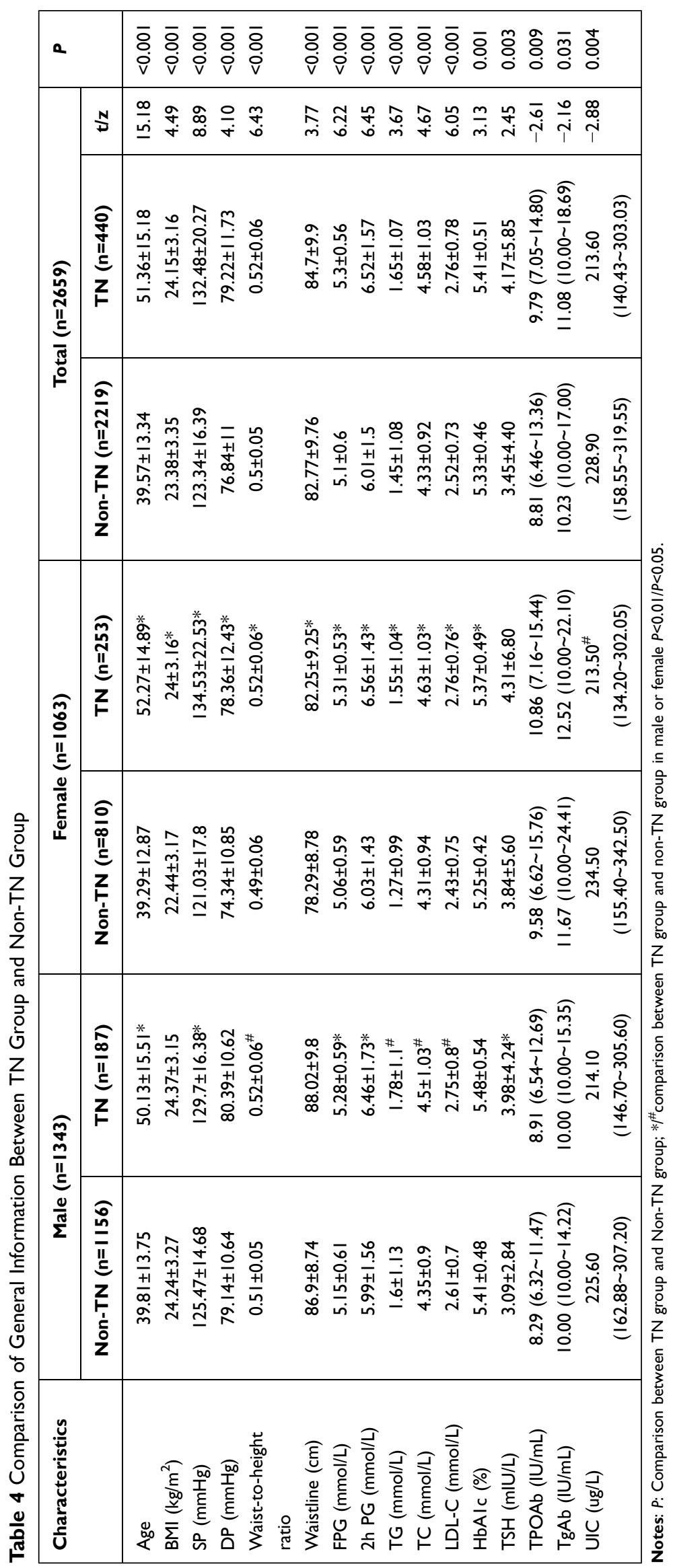


Table 5 Logistic Regression Analysis of Risk Factors for TN in Different Subtypes of Prediabetes Population

\begin{tabular}{|c|c|c|c|c|c|c|c|c|}
\hline \multirow[b]{2}{*}{ Characteristics } & \multicolumn{2}{|c|}{ PreDM } & \multicolumn{2}{|c|}{ IFG } & \multicolumn{2}{|c|}{ IGT } & \multicolumn{2}{|c|}{ IFG+IGT } \\
\hline & OR & $95 \% \mathrm{Cl}$ & OR & $95 \% \mathrm{Cl}$ & OR & $95 \% \mathrm{Cl}$ & OR & $95 \% \mathrm{Cl}$ \\
\hline Sex & 0.558 & $0.34 \sim 0.93 *$ & 0.443 & $0.22 \sim 0.88 *$ & 0.470 & $0.25 \sim 0.87^{*}$ & 0.668 & $0.20 \sim 2.22$ \\
\hline Age & 1.068 & $1.04 \sim 1.09 *$ & 1.054 & $1.01 \sim 1.10^{*}$ & 1.099 & $1.06 \sim 1.14^{*}$ & 1.092 & $1.03 \sim 1.16^{*}$ \\
\hline $\mathrm{SP}(\mathrm{mmHg})$ & 1.031 & $1.01 \sim 1.05^{*}$ & 1.033 & $1.01 \sim 1.07^{*}$ & 1.018 & $1.01 \sim 1.03 *$ & 1.026 & $1.01 \sim 1.04 *$ \\
\hline TSH (mIU/L) & 1.029 & $1.01 \sim 1.12 *$ & 1.328 & $1.02 \sim 1.76^{*}$ & 1.019 & $0.936 \sim 1.11$ & 0.837 & $0.63 \sim 1.21$ \\
\hline Family history (DM) & 1.834 & $1.01 \sim 3.36 *$ & 2.027 & $2.03 \sim 0.5 \mathrm{I}$ & 1.232 & $0.65 \sim 2.34$ & $0.74 I$ & $0.18 \sim 3.04$ \\
\hline HbAlc (\%) & 1.263 & $0.82 \sim 1.96$ & 1.082 & $0.37 \sim 3.12$ & 1.158 & $0.68 \sim 1.98$ & 5.982 & $1.15 \sim 31.17^{*}$ \\
\hline Hypertension & 1.808 & $1.09 \sim 2.98 *$ & 1.164 & $0.28 \sim 4.86$ & 1.416 & $0.75 \sim 2.67$ & 4.362 & $1.26 \sim 15.138^{*}$ \\
\hline LDL-C (mmol/L) & 1.378 & $1.02 \sim 1.88 *$ & 1.670 & $0.75 \sim 3.72$ & 1.107 & $0.74 \sim 1.65$ & 2.905 & I.I4 7.39* \\
\hline
\end{tabular}

Note: $* P<0.05$.

The results of this study showed that the detection rate of TN in the PreDM population was significantly higher than that of NGT $(24.48 \%$ vs $15.00 \%)$. Further gender stratification analysis of the PreDM population showed that this conclusion was also applicable, which was consistent with the results of Guo et $\mathrm{al}^{9}$ suggesting that elevated blood glucose might promote the formation of $\mathrm{TN}$, and the PreDM population should pay attention to the occurrence of $\mathrm{TN}$. We found that women were the risk factors of TN in IGT, suggesting that women with IGT should pay more attention to the prevention of $\mathrm{TN}$, which is consistent with Ding et $\mathrm{al}^{10}$ who found that the prevalence of TN in women with impaired glucose metabolism is higher, but not in men. It may be that testosterone helps to prevent the harmful effects of IGT on men. No matter what type of prediabetes subtypes, this study found that the detection rate of TN in PreDM group was significantly higher than that in NGT group, and the detection rate of $\mathrm{TN}$ in IFG+IGT group (32.20\%) was the highest. At the same time, HbA1c is a risk factor for TN in the IFG+IGT population. Blanc et $\mathrm{al}^{11}$ also found similar conclusions. Patients with abnormal glucose metabolism with higher HbA1c levels are more likely to suffer from TN, suggesting that for the IFG+IGT population, prevention and treatment of TN should be paid more attention, and HbAlc level may be the key indicator. Further analysis showed that the detection rate of TN in IFG, IGT and PreDM populations increased with age, especially in people over 61 years old. Age was also a risk factor for TN in PreDM and different subtypes. In this study, LDL-C was found to be a risk factor for TN in the PreDM population. Further comparative analysis showed that BMI, waist-height ratio, waist circumference, TG, TC, LDL-C and blood glucoserelated indexes (FPG, 2h PG, HbA1c) in the TN group were higher than those in the Non-TN group. Buscemi et $\mathrm{al}^{12}$ showed that obesity and diabetes can promote the occurrence of $\mathrm{TN}$, and further confirmed our results, suggesting that glucose and lipid metabolism is closely related to $\mathrm{TN}$, we should pay attention to the relationship between glucose and lipid metabolism and thyroid disease. Logistic regression analysis showed that the risk factors for TN in the PreDM population were hypertension, high SP and high TSH. Chen et $\mathrm{al}^{13}$ also showed that patients with hypertension were more susceptible to $\mathrm{TN}$, which is consistent with our study. Anil et $\mathrm{al}^{6}$ also found that people with impaired glucose metabolism had higher TSH levels, thyroid volume and nodule prevalence. Therefore, we should pay attention to the blood pressure and thyroid function of the PreDM population to reduce the incidence of TN.

PreDM may lead to a higher prevalence of $\mathrm{TN}$ : hypothalamus-pituitary-thyroid axis regulation disorder. The leptin level in the high blood glucose population increases. Leptin can increase TSH secretion by stimulating the hypothalamus-pituitary-thyroid axis. ${ }^{6,14}$ And also play a direct role by regulating the expression of TRH gene in the paraventricular nucleus, thereby affecting the growth and differentiation of thyroid cells, leading to the occurrence of TN. ${ }^{15}$ Insulin resistance (IR): PreDM is often accompanied by IR. IR is considered to be a key factor in the pathogenesis of impaired glucose metabolism, which is closely related to the increase of TN detection rate. ${ }^{16}$ Hyperinsulinemia: PreDM people have higher insulin levels under abnormal glucose metabolism. On the one hand, insulin promotes the increase of total leptin level, thereby increasing the TSH level, resulting in $\mathrm{TN}^{17}$ On the other hand, TSH and insulin/insulin-like growth factor 1 (IGF-1) signaling pathway together accelerate cell cycle 
to make cell proliferation, regulate gene expression and cause TN. ${ }^{18}$

\section{Conclusion}

In summary, $\mathrm{TN}$ is high in PreDM adults in Gansu Province, and the control of related risk factors should be paid attention to. Comprehensive attention should be paid to the effect of glucose and lipid metabolism and blood pressure levels on the occurrence and development of $\mathrm{TN}$, especially the early screening of $\mathrm{TN}$ for elderly women and the corresponding intervention measures.

\section{Data Sharing Statement}

The data that support the findings of this study are available from the corresponding author.

\section{Ethical Consideration}

We have obtained ethical approval and letter of cooperation from the Medical Ethics Research Committee of the First Affiliated Hospital of China Medical University, AFSOP-07-1.0-01), which was conducted in accordance with the Declaration of Helsinki.

All study participants are voluntarily being included to obtain informed consent. And all participants have passed written consent. All participants are informed of the confidentiality, purpose and importance of the information.

\section{Acknowledgments}

We would like to thank everyone who participated in this study and helped collect data. And to thank all the anonymous participants for responding to our questions. Xingyu Chang and Yaqi Wang are co-first authors for this study.

\section{Funding}

2020 special project for the central government to guide local science and technology development (innovative platform for improving the ability of prevention and control of frequently-occurring diseases in Gansu Province, China) which is funded by Gansu Province Endocrine Disease Clinical Medicine Research Center Construction Plan (20JR10FA667); Natural Science Foundation of Gansu Province (20JR10RA681); Lanzhou Science and Technology Development Guiding Plan Project (2019-ZD -38); National Health and Family Planning Commission Public Welfare Industry Scientific Research Project (201402005); Lanzhou University 2021 College Students Innovation and Entrepreneurship (20210060122).

\section{Disclosure}

The authors report no conflicts of interest in this work.

\section{References}

1. Jia W, Weng J, Zhu D, et al. Standards of medical care for type 2 diabetes in China 2019. Diabetes Metab Res Rev. 2019;35(6):e3158. doi:10.1002/dmrr.3158

2. Li Y, Teng D, Shi X, et al. Prevalence of diabetes recorded in mainland China using 2018 diagnostic criteria from the American Diabetes Association: national cross sectional study. BMJ. 2020;369 (m997). doi:10.1136/bmj.m997

3. Yang W, Lu J, Weng J, et al. Prevalence of diabetes among men and women in China. $N$ Engl $J$ Med. 2010;362(12):1090-1101. doi:10.1056/NEJMoa0908292

4. Grani G, Sponziello M, Pecce V, Ramundo V, Durante C. Contemporary thyroid nodule evaluation and management. $J$ Clin Endocrinol Metab. 2020;105(9):2869-2883. doi:10.1210/clinem/ dgaa322

5. Durante C, Grani G, Lamartina L, Filetti S, Mandel SJ, Cooper DS. The diagnosis and management of thyroid nodules: a review [published correction appears in JAMA. JAMA. 2018;319(9):914-924. doi:10.1001/jama.2018.0898

6. Anil C, Akkurt A, Ayturk S, Kut A, Gursoy A. Impaired glucose metabolism is a risk factor for increased thyroid volume and nodule prevalence in a mild-to-moderate iodine deficient area. Metabolism. 2013;62(7):970-975. doi:10.1016/j.metabol.2013.01.009

7. Haugen BR, Alexander EK, Bible KC, et al. 2015 American Thyroid Association Management Guidelines for adult patients with thyroid nodules and differentiated thyroid cancer: the American Thyroid Association Guidelines task force on thyroid nodules and differentiated thyroid cancer. Thyroid. 2016;26(1):1-133. doi:10.1089/ thy. 2015.0020

8. Kalra S, Aggarwal S, Khandelwal D. Thyroid dysfunction and Type 2 diabetes mellitus: screening strategies and implications for management. Diabetes Ther. 2019;10(6):2035-2044. doi:10.1007/ s13300-019-00700-4

9. Guo H, Sun M, He W, et al. The prevalence of thyroid nodules and its relationship with metabolic parameters in a Chinese community-based population aged over 40 years. Endocrine. 2014;45(2):230-235. doi:10.1007/s12020-013-9968-0

10. Ding X, Xu Y, Wang Y, et al. Gender disparity in the relationship between prevalence of thyroid nodules and metabolic syndrome components: the SHDC-CDPC Community-Based Study. Mediators Inflamm. 2017;2017:8481049. doi:10.1155/2017/8481049

11. Blanc E, Ponce C, Brodschi D, et al. Association between worse metabolic control and increased thyroid volume and nodular disease in elderly adults with metabolic syndrome. Metab Syndr Relat Disord. 2015;13(5):221-226. doi:10.1089/met.2014.0158

12. Buscemi S, Massenti FM, Vasto S, et al. Association of obesity and diabetes with thyroid nodules. Endocrine. 2018;60(2):339-347. doi:10.1007/s12020-017-1394-2

13. Chen Y, Zhu C, Chen Y, et al. The association of thyroid nodules with metabolic status: a cross-sectional SPECT-China Study. Int J Endocrinol. 2018;2018:6853617. doi:10.1155/2018/6853617

14. Sandoval DA, Davis SN. Leptin: metabolic control and regulation. J Diabetes Complications. 2003;17(2):108-113. doi:10.1016/S10568727(02)00167-8

15. Sousa PA, Vaisman M, Carneiro JR, et al. Prevalence of goiter and thyroid nodular disease in patients with class III obesity. Arq Bras Endocrinol Metabol. 2013;57(2):120-125. doi:10.1590/S0004-27302013000200004

16. Santini F, Marzullo P, Rotondi M, et al. Mechanisms in endocrinology: the crosstalk between thyroid gland and adipose tissue: signal integration in health and disease. Eur $J$ Endocrinol. 2014;171(4): R137-R152. doi:10.1530/EJE-14-0067 
17. Iglesias-Osma MC, Blanco EJ, Carretero-Hernandez M, et al. The influence of the lack of insulin receptor substrate 2 (IRS2) on the thyroid gland. Sci Rep. 2019;9(1):5673. doi:10.1038/s41598-019-42198-7
18. Mullur R, Liu YY, Brent GA. Thyroid hormone regulation of metabolism. Physiol Rev. 2014;94(2):355-382. doi:10.1152/ physrev.00030.2013
Risk Management and Healthcare Policy

\section{Publish your work in this journal}

Risk Management and Healthcare Policy is an international, peerreviewed, open access journal focusing on all aspects of public health, policy, and preventative measures to promote good health and improve morbidity and mortality in the population. The journal welcomes submitted papers covering original research, basic science, clinical \& epidemiological studies, reviews and evaluations,

\section{Dovepress}

guidelines, expert opinion and commentary, case reports and extended reports. The manuscript management system is completely online and includes a very quick and fair peer-review system, which is all easy to use. Visit http://www.dovepress.com/testimonials.php to read real quotes from published authors. 